\title{
Performance Comparison of 12S-14P Inner and Outer Rotor Field Excitation Flux Switching Motor
}

\author{
Syed Muhammad Naufal Syed Othman ${ }^{\mathrm{a}}$, Erwan Sulaiman ${ }^{\mathrm{b}}$, Faisal Khan ${ }^{\mathrm{c}}$, \\ Zhafir Aizat Husin ${ }^{\mathrm{d}}$ and Mohamed Mubin Aizat Mazlan ${ }^{\mathrm{e}}$
}

\author{
Department of Electrical Power Engineering, Universiti Tun Hussein Onn Malaysia, Locked Bag \\ 101, Batu Pahat, Johor, 86400 Malaysia
}

age130092@siswa.uthm.edu.my, berwan@uthm.edu.my, ${ }^{\mathrm{c}}$ faisalkhan@ciit.net.pk, 'zhafiraizat69@gmail.com, ${ }^{\mathrm{e}}$ mubinaizat@gmail.com

Keywords: Field excitation, flux switching motor, outer rotor, inner rotor,

\begin{abstract}
Hybrid excitation flux switching machines (HEFSMs) have a several advantages such as robust rotor structure, high torque and power capabilities, and high efficiency suitable for light load and heavy industry applications. However, the general structure of HEFSMs employed with three main flux sources namely permanent magnet (PM), field excitation coil (FEC) and armature coil located on the stator body causes high manufacturing cost. Therefore, a new non-PM field excitation flux switching machine (FEFSM) consists of rugged rotor structure suitable for highspeed operation with capability to keep similar torque and power density of HEFSM is proposed and examined. In this paper, performances of both outer and inner rotor 12S-14P FEFSMs are analyzed and compared. As conclusion, the inner-rotor topology provides much higher torque and power when compared with outer rotor configuration.
\end{abstract}

\section{Introduction}

Electric motors with high torque and power density capabilities are essential for heavy load applications such as in aerospace and automotive traction system [1]. Previously, permanent magnet (PM) brushless machines are widely used for these applications due to their advantages of high efficiency and smaller motor size. Nevertheless, due to the main flux source of PM is located on the rotor, the machine suffers from PM demagnetization effects, high eddy current losses and difficulty to dissolve heat from the rotating part.

In recent years, flux-switching motors (FSMs) become an attractive research topic due to several advantages of robust rotor structure, easy temperature management of all active parts on the stator as well as the ability to keep higher torque/power density and efficiency. Various applications of FSMs have been reported ranging from wind power generation, automotive, aerospace, power tools and etc [2]. Generally, FSMs can be classified into three groups, namely permanent magnet (PM) FSMs, hybrid excitation (HE) FSMs, and field excitation (FE) FSMs as shown in Fig. 1. Both PMFSMs and FEFSMs have only single excitation flux source which come from PM and FE coil, respectively, while for HEFSMs the main magnetic flux sources are generated from both PM and FECs [3].

Most of researchers focused on inner-rotor configuration [4-7] and left a vacant space in the area of outer-rotor FSM. Recently, a report on outer-rotor PMFSM has been published and the specification of the proposed machine is used for light traction EV applications [8-9]. However, with single magnetic flux source of constant PM, it also may suffer from demagnetization effect and uncontrollable flux. Initial design of an outer-rotor HEFSM with 12Slot-10Pole configuration has been described in [10]. The main problem associated with this machine is high cost due to PM and windings.

To overcome these problems, new structures of 12S-14P outer-rotor and inner rotor fieldexcitation flux switching motor are proposed, in which the permanent magnet is replaced by field excitation coil. Based on 2-D analysis demonstrated, the proposed machines have good torque and power capability to be applied in high speed applications. 


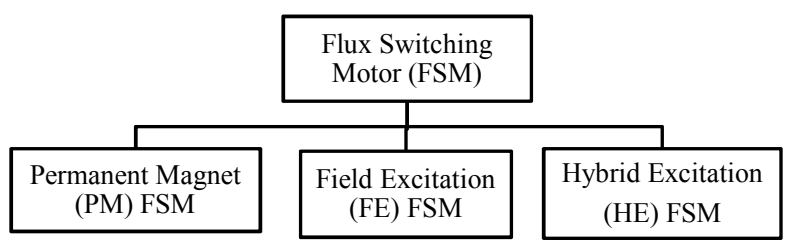

Fig. 1 Classification of Flux Switching Motor (FSM)

\section{Operating Principle of Flux Switching Motor}

The operating principle of the outer rotor FEFSM is illustrated in Fig. 2. Fig. 2 (a) and (b) show the direction of the FEC fluxes into the rotor while Fig. 2 (c) and (d) illustrate the direction of FEC fluxes into the stator which produces a complete one cycle flux. Similarly, the concept for the inner rotor is same like outer rotor topology and its just the position of the rotor that differentiate both the designs. As in general FSM, the flux linkage of FEC switches its polarity by following the movement of salient pole rotor which creates the term "flux switching". Each reversal of armature current shown by the transition between Fig. 2(a) and (b), causes the stator flux to switch between the alternate stator teeth [11-12].

\section{Design Performance and Results Based on 2D Finite Element Analysis}

FEC Flux Linkage at various FEC current densities, $\mathbf{J}_{\mathbf{E}}$. The DC FEC flux linkage at various DC FEC current densities, $J_{\mathrm{E}}$ for both inner and outer rotor are also investigated, as illustrated in Fig. 3(a) and (b), respectively. From the figures, it is clear that initially the flux pattern is increased with the increase in DC FEC current density, $\mathrm{J}_{\mathrm{E}}$. However, the flux generated starts to reduce when higher DC FEC current density is injected to the outer-rotor FEFSM as demonstrated in Fig. 4. It is expected that this phenomena occurs due to some flux leakage and flux cancellation that will be investigated in future. In addition, the flux generated from inner rotor is higher than outer rotor FEFSM.

The flux distribution at zero rotor position of DC FEC for both inner and outer-rotor FEFSM are illustrated in Fig. 5. From the figure, it is obvious that large amount of flux easily flow from stator to rotor and return to stator for outer rotor while for inner rotor at the same amount of current, the flux linkage is less and the stator core gets saturated as indicated by red circle. The flux linkage of $12 \mathrm{~S}-14 \mathrm{P}$ of inner rotor can be improved by design refinement and optimization.

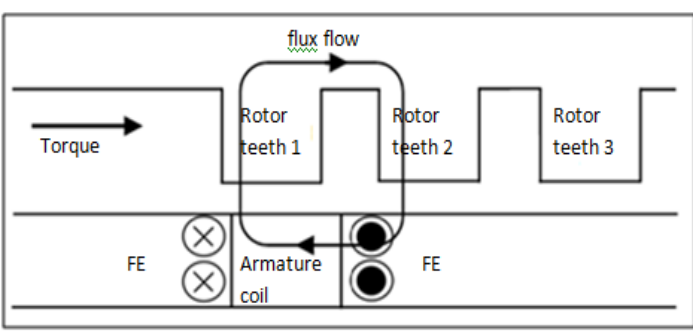

(a)

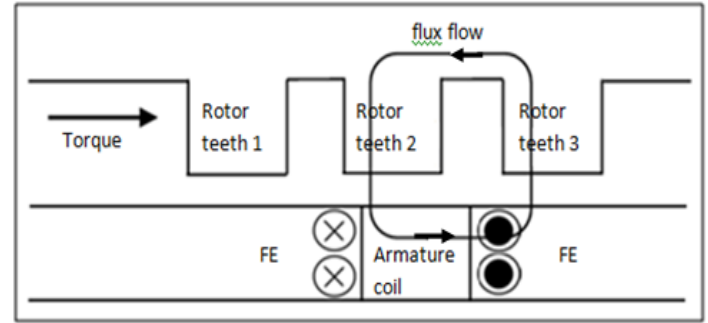

(c)

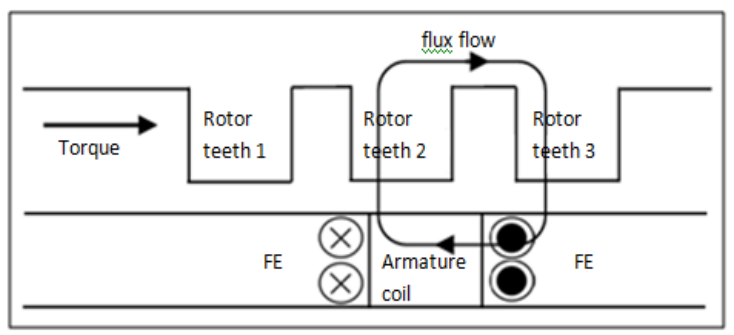

(b)

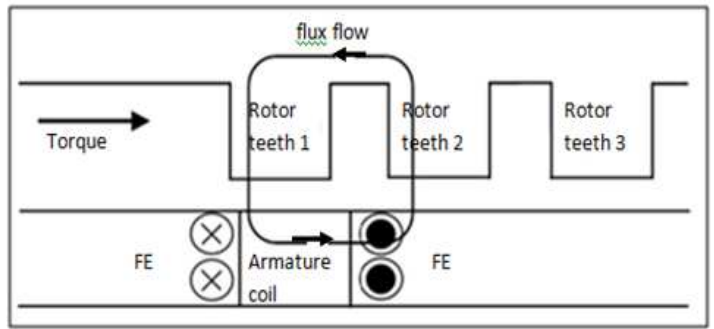

(d)

Fig. 2 Operating principle of outer-rotor FEFSM (a) $\theta e=0^{\circ}$ and (b) $\theta e=180^{\circ}$ flux moves from stator to rotor (c) $\theta e=0^{\circ}$ and (d) $\theta e=180^{\circ}$ flux moves from rotor to stator 


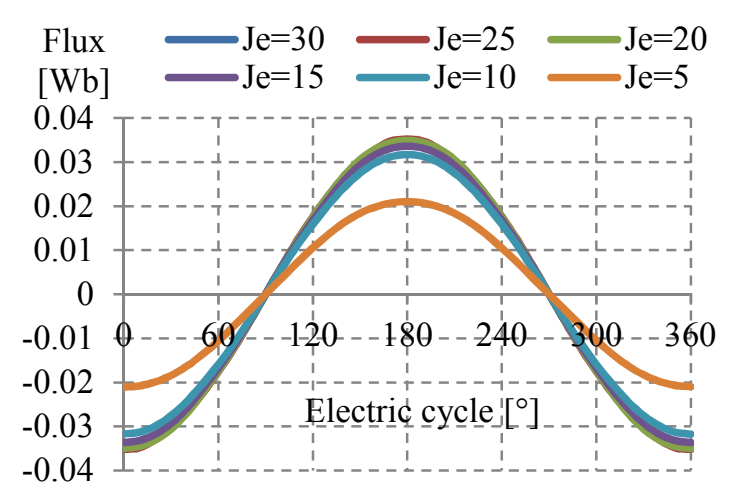

(a)

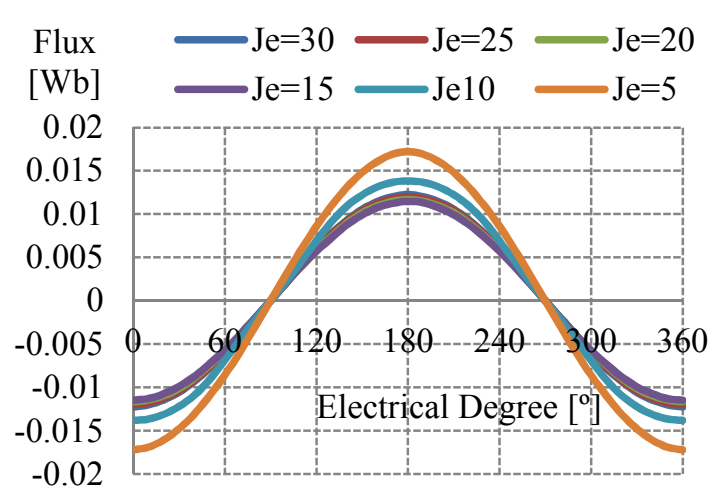

(b)

Fig. 3 Flux linkage at various DC FEC current densities, $J_{E}(a)$ Inner rotor (b) Outer Rotor

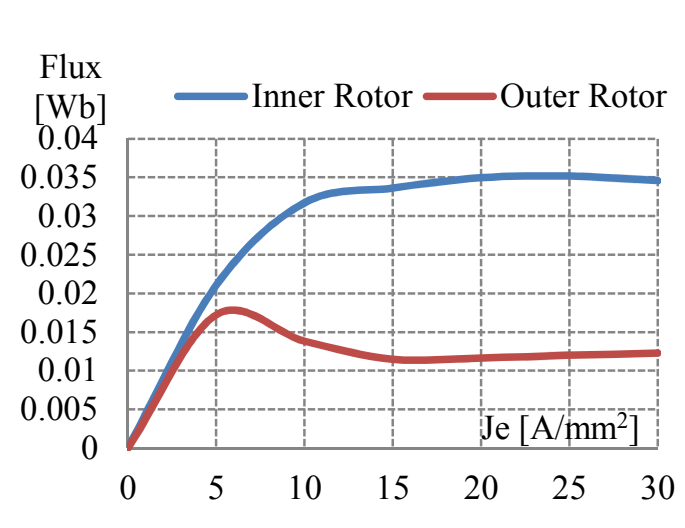

Fig. 4 Maximum U-flux at maximum $\mathrm{J}_{\mathrm{E}}$

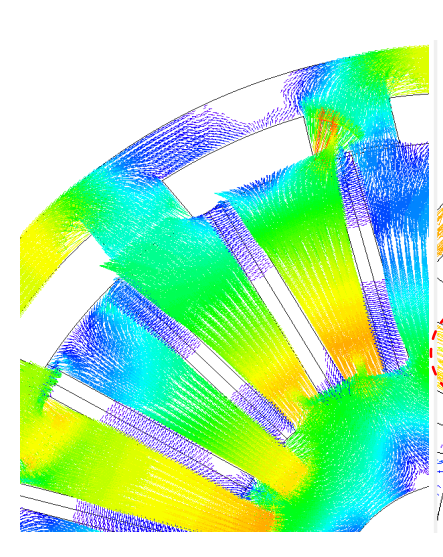

(a)

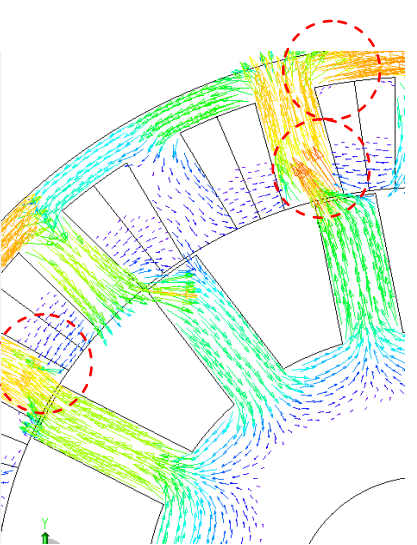

(b)

Fig. 5 Flux distribution of FEFSM (a)

Outer-Rotor (b) Inner Rotor

Induced Voltage and Cogging Torque at Open Circuit Condition. The amplitude of induced voltage generated from inner and outer rotor 12S-14P FEFSMs are plotted in Fig. 6. At open circuit condition under maximum DC FEC current densities, $\mathrm{J}_{\mathrm{E}}$, the induced voltage generated by inner rotor FEFSM is $100 \mathrm{~V}$ which is approximately two times more than the outer rotor FEFSM. The induced voltages of both designs are less than the applied voltage which makes it easy to provide protection for switching devices while the inverter is in off state due to some faults.

Fig. 7 depicts the evaluation between cogging torque of inner rotor and outer rotor $12 \mathrm{~S}-14 \mathrm{P}$ FEFSMs . From the graph, it can be noticed that 12S-14P with inner rotor has highest peak to peak cogging torque of $5.39 \mathrm{Nm}$ while outer rotor has $4.2 \mathrm{Nm}$, correspondingly. High vibration and noise
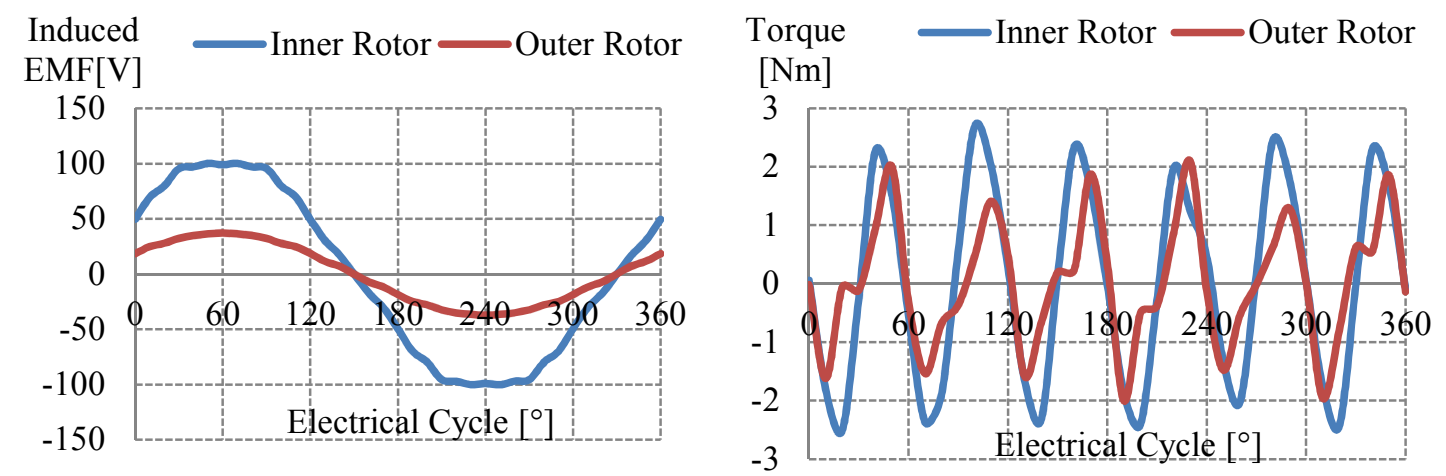

Fig. 6 Induced Voltages for FEFSM

Fig. 7 Cogging Torque 
will occur and the performances of FEFSMs will be affected, if the cogging torque exceeds $10 \%$ of the average torque produced. The cogging torque of both designs can be reduced by rotor skewing and rotor-pole pairing .

Average Torque and Power Characteristics. The 2D-FEA computed electromagnetic torque and power at maximum armature current density, $\mathrm{J}_{\mathrm{A}}$ are plotted in Fig. 8 and Fig. 9 versus different FEC current densities, $\mathrm{J}_{\mathrm{E}}$. It can be seen from the figures that by employing inner rotor, 12S-14P FEFSM has achieved torque of $164.08 \mathrm{Nm}$ and power of $88.25 \mathrm{~kW}$ higher than outer rotor FEFSM. The main reason is that negative torque is produced due to cancellation of fluxes between FECs and armature coils. Thus, it is essential to do further investigation to identify the problems of inner rotor configuration.

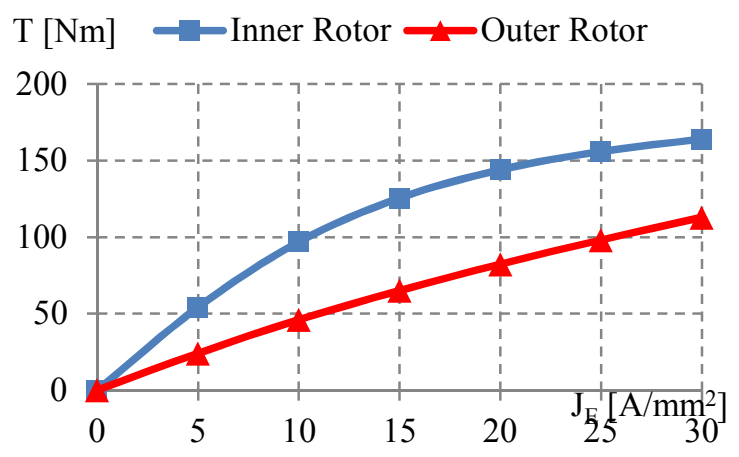

Fig. 8 Maximum Torque at various, $\mathrm{J}_{\mathrm{E}}$

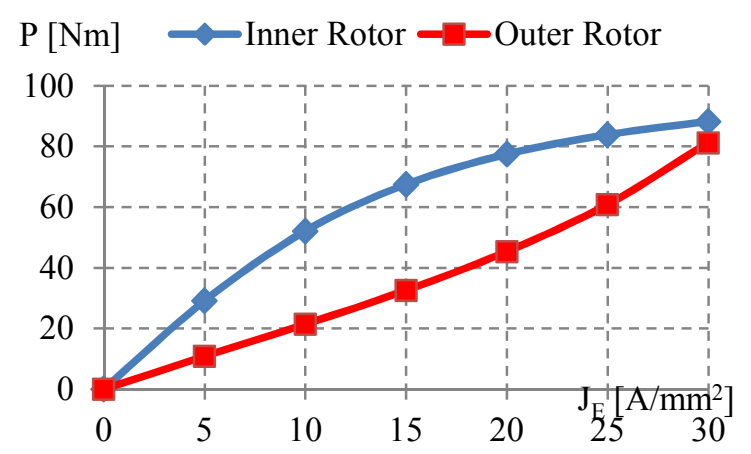

Fig. 9 Maximum Power at various, $\mathrm{J}_{\mathrm{E}}$

\section{Conclusion}

Design and performance comparison of 12S-14P with inner and outer rotor FEFSMs have been proposed and investigated in this paper. The proposed machine has no PM and in consequence, it can be anticipated as very cost-effective machine as well as simple structure. In addition, the generated flux can be controlled with variable capabilities through the presence of FEC. As conclusion, the inner rotor has much higher torque and power, approximately $31.16 \%$ and $6.96 \%$ of outer rotor FEFSM.

\section{References}

[1] Z. Q. Zhu and D. Howe, Electrical machines and drives for electric, hybrid, and fuel cell vehicles, Proc. IEEE, 95(2007) 746-765.

[2] Y. Amara, E. Hoang, M. Gabsi, and M. Lecrivain, Design and comparison of different fluxswitching synchronous machines for an aircraft oil breather application, Euro. Trans Electr. Powe, 15 (2005) 497-511.

[3] E. Sulaiman, T. Kosaka, and N Matsui, High power density design of 6slot-8pole hybrid excitation flux switching machine for hybrid electric vehicles, IEEE Trans. on Magn. 47 (2011) 4453-4456.

[4] C. Pollock and M. Brackley, Comparison of the acoustic noise of flux-switching and switched reluctance drive, IEEE Trans. Ind. Appl., 39 (2003) 826-834.

[5] W. Xu, J. Zhu, Y. Zhang, Y. Wang, Y. Li, and J. Hu, Flux-switching permanent magnet machine drive system for plug-in hybrid electrical vehicle, Proc. of IEEE Conf. on Australian Universities Power Engineering (AUPEC), (2010) 1-6.

[6] J.T. Chen and Z.Q. Zhu, Winding configuration and optimal stator rotor pole combination of flux-switching PM brushless machines, IEEE Trans. on Energy Conversion, 25 (2010) 293-302. 
[7] Y. Wang and Z. Deng, Comparison of hybrid excitation topologies for flux-switching machines, IEEE Trans. on Magn., 48 (2012) 2518-2527.

[8] E. Sulaiman, T. Kosaka, and N. Matsui, Design Optimization of 12Slot-10Pole hybrid excitation flux switching synchronous machine with $0.4 \mathrm{~kg}$ permanent magnet for hybrid electric vehicles, Proc. of International IEEE Conference on Power Electronics and ECCE Asia (ICPE \& ECCE), (2011) 1913-1920.

[9] W.Fei, P.C.K. Luk, J. Shen, and Y. Wang, A Novel Outer-Rotor Permanent-Magnet FluxSwitching Machine for Urban Electric Vehicle Propulsion, in 3rd International Conference on Power Electronics Systems and Applications (PESA), (2009) 1-6.

[10] M.Z. Ahmad, E. Sulaiman, Z.A. Haron, and T. Kosaka, Preliminary Studies on a New OuterRotor Permanent Magnet Flux Switching Machine with Hybrid Excitation Flux for Direct Drive EV Applications, IEEE Int. Power and Energy Conference (PECON2012), (2012) 928-933.

[11]E. Sulaiman, T. Kosaka, N. Matsui, and M. Z. Ahmad, Design Studies on High Torque and High Power Density Hybrid Excitation Flux Switching Synchronous Motor for HEV Applications, in IEEE International Power Engineering and Optimization Conference (PEOCO), (2012) 333-338.

[12]E. Sulaiman, M. F. M. Teridi, Z. A. Husin, M. Z. Ahmad and T. Kosaka, Performances Comparison of 24S-10P and 24S-14P Field Excitation Flux Switching Machine (FEFSM) With Single DC-Coil Polarity, International Journal of Energy \& Power Engineering Research, 01 (2013) 24-31 